\title{
Is pedometer-determined day-of-the-week variability of step counts related to age and BMI in Czech men and women aged 50 to 70 years?
}

\author{
Jana Pelclová1,*, Karel Frömel ${ }^{1}$, Emil Řepka², Ladislav Bláha ${ }^{3}$, Aleš Suchomel ${ }^{4}$, Igor Fojtík ${ }^{5}$, \\ Dana Feltlová 6 , Petr Valach ${ }^{7}$, Svatopluk Horák ${ }^{1}$, and Jiř́i Nykodým ${ }^{8}$ \\ ${ }^{1}$ Faculty of Physical Culture, Palacký University Olomouc, Olomouc, Czech Republic; ${ }^{2}$ Faculty of Education, University of

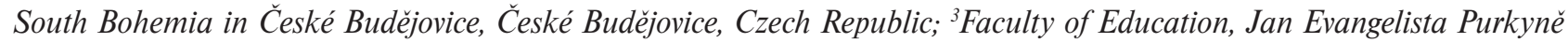 \\ University in Ústí nad Labem, Ústí nad Labem, Czech Republic; ${ }^{4}$ Faculty of Science, Humanities and Education, Techni- \\ cal University of Liberec, Liberec, Czech Republic; ${ }^{5}$ Pedagogical Faculty, University of Ostrava, Ostrava, Czech Republic; \\ ${ }^{6}$ Faculty of Education, University of Hradec Králové, Hradec Králové, Czech Republic; ${ }^{7}$ Faculty of Education, University of \\ West Bohemia, Plzen̆, Czech Republic; and ${ }^{8}$ Faculty of Sports Studies, Masaryk University, Brno, Czech Republic
}

Copyright: (C) 2016 J. Pelclová et al. This is an open access article licensed under the Creative Commons Attribution License (http://creativecommons.org/licenses/by/4.0/).

\begin{abstract}
Background: Day-to-day walking variability appears not to be random and may fluctuate by day of week or type of day (workdays/non-workdays). The day-of-the-week variability is less clear in period of life transition between the ages of 50-70 years. Moreover, it is unclear whether the variability is related to age or BMI. Objective: The aim of this study was to identify the weekdays-weekends patterns and the day-to-day variability in step patterns in men and women of different age and BMI groups. Methods: During the years 2009-2012, 1,170 individuals (532 men and 638 women) aged 50-70 years participated in a seven-day monitoring using a Yamax Digiwalker SW-700 pedometer. Results: Using ANOVA of repeated measures, it was found that steps/day varied across the day of the week in both men and women in younger age groups ( $\leq 64$ years) $(p \leq .04)$, whereas in older age group (65-70 years), no significant systematic variability by day of the week was found. Existence of variability by day of the week with significant drop in steps/day on weekend days, especially on Sunday, was confirmed in normal weight, overweight and obese Czech men and women. Conclusion: In conclusion, this study contributes to the evidence with the findings about the existing the day-of-the-week variability of step counts per day in the population aged 50 to 64 years and about the absence of significant variability in seniors ( $\geq 65$ years). Sunday was the least active day in different age and BMI groups aged 50 to 70 years of Czech population. Researchers and practitioners should take the results of this study into consideration when preparing for data collection of habitual physical activity in senior population and in the development of walking interventions and weight reduction programmes designed for this age group.
\end{abstract}

Keywords: adults, older adults, walking, overweight, obesity, weekdays, weekends

\section{Introduction}

In recent years, pedometers have been accepted in the exercise science community as a tool for measuring physical activity across different age populations. Pedometers are most accurate in estimating the number of steps (Crouter, Schneider, Karabulut, \& Bassett, 2003) and thus, can be used for assessment of walking. Walking as a natural form of daily locomotion,

\footnotetext{
* Address for correspondence: Jana Pelclová, Institute of Active Lifestyle, Faculty of Physical Culture, Palacký University Olomouc, třída Míru 117, 77111 Olomouc, Czech Republic. E-mail: jana.pelclova@upol.cz
}

commonly reported activity in leisure time and a main part of active transportation activities provides possibilities for public health initiatives in mainly adult and senior populations (Pelclová, 2015). However, walking day-to-day variability appears not to be random. Volume of steps/day depends on gender and may fluctuate by day of week (weekdays-weekends), type of day (workdays-non-workdays), and by sport/exercise participation (Tudor-Locke et al., 2004). Extensive evidence in studies on children indicated that girls were less active than boys (Riddoch et al., 2007) and both sexes were less active at weekends than on weekdays (Rowlands, Pilgrim, \& Eston, 2008), with a tendency for girls' activity to drop off more steeply at the weekend 
compared to boys (Rowlands et al., 2008). Similarly in adolescents, boys were less sedentary and more active than girls. Adolescents were also less active on weekdays than during weekends (Peiró-Velert, DevísDevís, Beltrán-Carrillo, \& Fox, 2008; Pelclová, El Ansari, \& Vašičková, 2010). Furthermore, consistent gender differences were found in activity levels in all days of the week except on Sunday, especially for the late afternoon period (Jago, Anderson, Baranowski, \& Watson, 2005). Low weekend - high weekday patterns were observed also in adults with Saturday (Matthews, Ainsworth, Thompson, \& Bassett, 2002) or Sunday (Clemes, Griffiths, \& Hamilton, 2007) as the least active day. Considering day-to-day variability and weekday-weekend patterns, there is more limited evidence in older adult populations. Rowe, Kemble, Robinson, and Mahar (2007) indicated that objectively measured physical activity behavior in seniors (aged 60+) is less variable than in younger populations. Day-to-day walking and time on feet variability was also very low with no differences between weekdays and weekend days in 44 community dwelling older adults (Nicolai et al., 2010). Furthermore, minimal overall effects of the day of the week were seen in men and women aged 65-85 years during one year (Togo et al., 2008).

The period between 50 and 70 years of age is identified as a transition period because an individual usually changes from a parental to a grand-parental status (Vágnerová, 2007) and especially undergoes the most prominent socially conditioned change from an employed to a retired status (Schellenberg, Turcotte, \& Ram, 2005). Transition to retirement could be associated with significant changes in type, volume or intensity of physical activity. For instance in Finnish study (Lahti, Laaksonen, Lahelma, \& Rahkonen, 2011), transition to retirement was associated with an increase in moderate-intensity leisure-time physical activity and a decrease in the proportion of inactive. Conversely, the findings of the GLOBE study (Slingerland et al., 2007), in which the participants were monitored for a period of 13 years, confirm a decrease in work-related active transport (walking, cycling) after retirement, which was not substituted with another type of leisure physical activity. Similarly, a Czech study (Pelclová et al., 2008) investigating physical activity and sitting time in employees and retirees suggests that walking performed to commute to work and back and during work-related activities significantly contributes to the daily amount of walking. In addition to social changes in the period between 50-70 years of age, there are also obvious body composition changes with high risk for abdominal fat gain related to menopausal transition and several years after menopause in women (Lovejoy, Champagne, De Jonge, Xie, \& Smith, 2008).
Obesity is a major health problem worldwide $(\mathrm{Ng}$ et al., 2014). Physical activity plays crucial role in its prevention (Miles, 2007; Physical Activity Guidelines Advisory Committee, 2008) and hence, it is essential to understand the activity patterns in relation to obesity. For overweight and obesity classification, body mass index (BMI) is commonly used. World Health Organization (World Health Organization, 2006) stated the principal cut-off points of BMI that should be age-independent and the same for both sexes. However, few studies investigated the day-of-the-week variability of step counts related to BMI or other body composition variables. Clemes et al. (2007) identified no day-of-the-week effect in normal weight participants and significantly lower daily step counts accumulated on Sunday in the overweight group. In another study in UK adults, there were observed no differences in step counts between the overweight and obese groups. However, consistent reduction in activity on Sundays was observed in all participants with this reduction being two-fold greater in overweight and obese groups when compared with the normal-weight group (Clemes, Hamilton, \& Lindley, 2008). Moreover, the study of normal-weight and obese adults revealed that significant day-of-the-week effect could be observed during both summer and winter seasons in the overweight group, but only in winter in the normal-weight group (Clemes, Hamilton, \& Griffiths, 2011).

In comparison with other countries, the Czech built environment is highly walkable (Van Dyck et al., 2015) with a possible impact on body composition (Sofková, Přidalová, \& Pelclová, 2014) and thus, suitable for transport or leisure time walking interventions. In the context of the future increase in the proportion of the senior population predicted by the Czech Statistical Office (2009), regular walking performed by older adults might have a positive effect not only on their health but also their social and mental well-being, prolong self-sufficient living and thus reduce healthcare expenditures (U.S. Department of Health and Human Services, 2000). Also in the "National action plan promoting positive ageing 2013-2017" (Czech Ministry of Labour and Social Affairs, 2012), Healthy ageing section emphasises the necessity to target preventive programmes in the population of 50-year-old and older inhabitants of the Czech Republic. To date, only few interventions focusing on Czech 50-70 year old Czech inhabitants have been carried out (Cuberek et al., 2014). In connection with the great walkable potential of the Czech environment, better understanding of day-to-day variability in step patterns in different age groups in population aged 50 to 70 years might increase the effectiveness of particularly walking intervention programmes in terms of their translating into 
practise. Moreover, the recommended amount of walking might be an effective way for reducing obesity in the over 50 Czech population (Pelclová, Gába, Tlučáková, \& Pośpiech, 2012). To our knowledge, a study reporting day-to-day variability in daily steps of 50-70 year old Czech men and women has not been published yet.

Therefore, the aim of this study was to identify the day-to-day variability in step patterns in men and women of different age groups (50 years, 51-54 years, 55-59 years, 60-64 years, and 65-70 years) and BMI groups (normal weight, overweight, obese).

\section{Methods}

\section{Participants and setting}

This cross-sectional descriptive study was approved by the Ethics Committee of the Faculty of Physical Culture, Palacký University Olomouc. The study was carried out during the years 2009-2012. Monitoring was undertaken during the spring and autumn (seasons with comparable weather conditions in the Czech Republic) to avoid possible weather influences (Belza et al., 2004). Addresses within all regions of the Czech Republic were randomly selected on the webpages of the Ministry of the Interior of the Czech Republic. Trained research coordinators visited each selected household and family members ( $\geq 50$ years old) were informed about the study aims and offered to participate. In case of agreement, each participant signed an informed consent. This type of sample selection within the Czech Republic has been published previously (Frömel, Mitáš, \& Kerr, 2009; Pelclová, Frömel, \& Cuberek, 2014; Sigmundová, El Ansari, \& Sigmund, 2011). The initial sample comprised 1,431 participants aged 50-70 years. 261 participants were excluded if they were: (1) reporting any disabilities, chronic conditions or using any prostheses; (2) not completing the whole week steps/day record. Hence, 1,170 participants (532 men and 638 women) were included into the study. The sample age and BMI characteristics is shown in Table 1 and Table 2.

\section{Measurements}

Physical activity

The objective measurement of physical activity (PA) was undertaken as a seven-day monitoring using Yamax Digiwalker SW-700 pedometer (Yamax Corporation, Tokyo, Japan). Participants wore the pedometers on the right side of their waist all day except for hygiene (e.g., showering, bathing) and swimming (the device is not waterproof). As pedometers are most accurate in estimating the number of steps and least accurate in estimating energy expenditure (Crouter et al., 2003),
Table 1

BMI characteristics of men and women according to the age groups

\begin{tabular}{lrccccccc}
\hline \multirow{2}{*}{$\begin{array}{l}\text { Age group } \\
\text { (years) }\end{array}$} & \multicolumn{3}{c}{ Men } & & \multicolumn{3}{c}{ Women } \\
\cline { 2 - 4 } \cline { 7 - 9 } & $n$ & $M$ & $S D$ & & $n$ & $M$ & $S D$ \\
\hline 50 & 144 & 27.34 & 3.61 & & 170 & 24.74 & 3.95 \\
$51-54$ & 166 & 26.92 & 3.47 & & 187 & 25.47 & 4.16 \\
$55-59$ & 109 & 27.74 & 3.32 & & 112 & 26.18 & 4.06 \\
$60-64$ & 54 & 27.48 & 3.48 & & 105 & 27.49 & 4.62 \\
$65-70$ & 59 & 27.78 & 4.57 & & 64 & 28.11 & 4.82 \\
\hline
\end{tabular}

Table 2

Age characteristics of men and women according to the BMI groups

\begin{tabular}{lrcccccc}
\hline & \multicolumn{3}{c}{ Men } & & \multicolumn{3}{c}{ Women } \\
\cline { 2 - 4 } \cline { 6 - 8 } BMI group & \multicolumn{1}{c}{$n$} & $M$ & $S D$ & & $n$ & $M$ & $S D$ \\
\hline Normal & 129 & 55.00 & 5.59 & & 305 & 54.27 & 5.33 \\
Overweight & 314 & 55.03 & 5.80 & & 219 & 55.43 & 5.68 \\
Obese & 89 & 55.38 & 5.98 & & 114 & 58.22 & 6.32 \\
\hline
\end{tabular}

the number of steps achieved was employed to express participants' achieved PA.

\section{Other data collection}

Body mass index (BMI) was calculated based on selfreported weight and height and was categorized as normal weight $\left(18.5-24.9 \mathrm{~kg} / \mathrm{m}^{2}\right)$, overweight (25$29.9 \mathrm{~kg} / \mathrm{m}^{2}$ ) and obese $\left(\geq 30 \mathrm{~kg} / \mathrm{m}^{2}\right.$ ) (World Health Organization, 2006). Moreover, additional information about date of birth was obtained from respondents.

\section{Data analysis}

The statistical package IBM SPSS Statistics (Version 22; IBM, Armonk, NY, USA) was used to statistically process the data. Significant levels were set at $p<.05$. As the data were found to be normally distributed for all variables examined, descriptive statistics were presented as means $(M)$, standard deviation $(S D)$ and confidence interval. Based on previous studies (Kang et al., 2009), an analysis of variance could be used for examining the sources of variation in step-count data (i.e. person, day of the week, season). Hence, repeated measures analysis of variance (ANOVA) and paired t-test were used to identify the differences between the steps achieved on working days and weekends overall and in different age and BMI groups, and between the steps performed by men and women. Furthermore, the repeated measures analysis of variance test with related Fisher LSD post-hoc test was used to examine 
the association between pedometer-determined physical activity and age separately for men and women. Participants were split into five age groups (50 years old, 51-54 years old, 55-59 years old, 60-64 years old, 65-70 years old). Regarding the high number of fifty-year-old participants, a separate group for this age category was deliberately established, although it might be anticipated that no significant differences will be identified between the group of 50-year-old participants and those aged 51 to 54 years. Repeated measures analysis of variance test with related Fisher LSD post-hoc test was also used for examination of the association between pedometer-determined physical activity and BMI (normal, overweight, obesity) separately for men and women. In a Czech study of adults and older adults, the diagnostic performance of BMI did not differ as age increased (Gába \& Přidalová, 2015). Hence, BMI groups were classified in this study according World Health Organization (2006) cut-offs regardless of age. The coefficient $\omega^{2}$ and coefficient $d$ were calculated as indicators of effect size. According to suggestion of Cohen (1988), the coefficient $\omega^{2}$ values of $0.01,0.06$ and 0.14 were interpreted as small, medium and large effect. According to Sheskin (2007), the coefficient $d$ values of $0.2,0.5$ and 0.8 were interpreted as small, medium and large effect.

\section{Results}

Differences in pedometer-determined physical activity between weekdays and weekend days

The Czech sample of adults and older adults achieved on average 8,972 $\pm 3,655$ steps/day. Means and confidence intervals of steps/day values on weekdays, weekend days and overall in men and women are depicted in Figure 1. Men $(M=9,391 ; S D=3,909)$ achieved significantly more steps/day than women $(M=$ $8,621 ; S D=3,392)$ in all days of the week $(F=13.01$; $p<.001 ; \omega^{2}=0.01$ ), on weekdays (men $M=9,532$;

a) Men

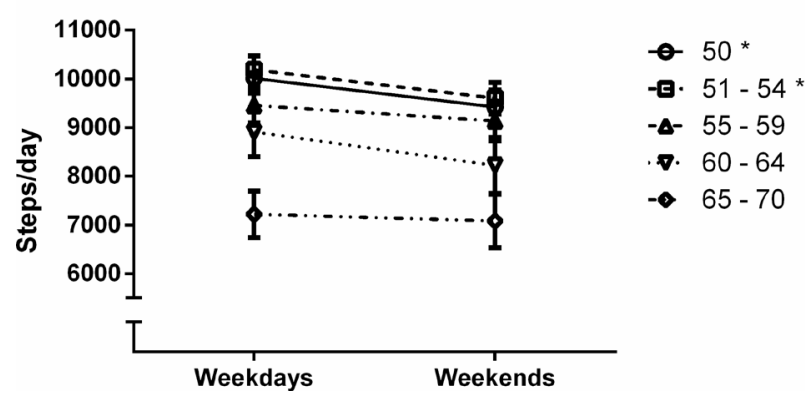

$S D=4,025$; women $M=8,804 ; S D=3,551 ; F=10.79$; $p=.001 ; \omega^{2}=0.01$ ) and on weekends (men $M=9,039$; $S D=4,686$; women $M=8,164 ; S D=3,947 ; F=12.04$; $\left.p<.001 ; \omega^{2}=0.01\right)$. Both men and women achieved significantly more steps/day on weekdays than on weekend days (men $t=3.21, p=.001, d=0.19$; women $t=5.23, p<.001, d=0.31)$.

Differences in steps/day values between weekdays and weekends were compared in men and women of different age groups. Means and standard deviations are shown in Figure 1. Statistically significant differences between mean steps achieved on weekdays and weekends were found in fifty-year-old men $(p=.03)$ and men aged 51-54 years (0.02) and fifty-year-old women $(p=0.005)$ and women aged 55-59 years $(p=0.001)$.

Differences in means and standard deviations of steps/day values on weekdays and weekend days in men and women of different BMI groups are shown in Figure 2. Statistically significant differences between steps/day achieved on weekdays and weekend were found in both overweight men $(p=.004)$ and women $(p<.001)$ and in women with normal BMI $(p=.02)$.

Variability of pedometer-determined physical activity on various days of the week in different age groups

Figure 3 depicts the variability by day of the week in five age groups in men and women. The repeated ANOVA showed statistically significant differences for day of the week $\left(F=3.32, p=.003, \omega^{2}=0.04\right)$ and age groups in men $\left(F=6.99, p<.001, \omega^{2}=0.04\right)$. The interaction between day of the week and age groups was not significant. The LSD post-hoc test suggested that men from the first age group achieved significantly more steps/day on Tuesday $(p \leq .02)$ and Wednesday ( $p \leq .02)$ compared to Friday, Saturday and Sunday. For men from the second age group (51-54 years), the least active day was Sunday compared to Tuesday $(p=.04)$, Wednesday $(p=.003)$, Thursday $(p=.005)$ and Friday $(p=.006)$. Men from the third group achieved significantly more steps/day on Wednesday

b) Women

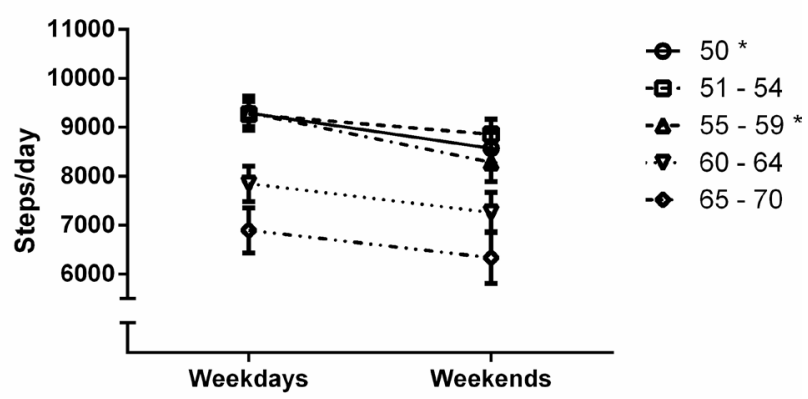

Figure 1. Differences in means and standard deviations of steps/day values on weekdays and weekend days in men (a) and women (b) of different age groups $(* \mathrm{p}<.05)$. 
compared to Monday $(p=.03)$ and Saturday $(p=.04)$. For men from the fourth age group (61-64 years), Sunday was the least active day compared to Wednesday $(p=.01)$ and Friday $(p=.003)$. No significant differences in the number of days of the week were found in the oldest men (65-70 years).

The repeated ANOVA showed statistically significant differences for day of the week $(F=6.59, p<.001$, $\left.\omega^{2}=0.05\right)$ and age groups in women $(F=9.76, p<.001$, $\left.\omega^{2}=0.05\right)$. The interaction between day of the week and age groups was not significant. According to the LSD post-hoc test, women from the first age group (50 years) achieved significantly more steps/day in all five weekdays compared to Sunday $(p \leq .03)$ and on Wednesday compared to Saturday $(p=.03)$. Women from the second age group achieved significantly more steps/day on Tuesday compared to Friday, Saturday and Sunday $(p \leq .04)$. For women from the third age group (55-59 years), Sunday was the significantly least active day compared to all five weekdays $(p \leq .02)$. Moreover, women from the third group achieved significantly more steps/day on Thursday compared to Saturday $(p=.01)$. Women from the fourth age group achieved significantly more steps/day on Wednesday compared to Sunday ( $p=.009)$. No significant differences in the number of days of the week were found in the oldest women (65-70 years).

a) Men

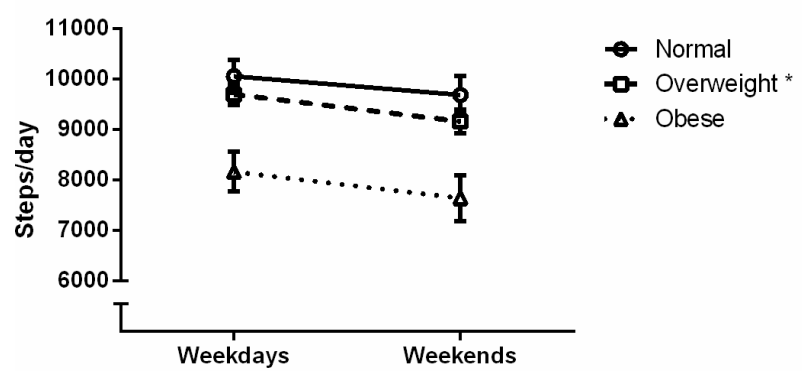

Variability of physical activity on various days of the week in persons with normal weight, overweight and obesity

Figure 4 depicts the variability by day of the week in three BMI groups in men and women. The repeated ANOVA showed statistically significant differences for day of the week $\left(F=3.11, p=.005, \omega^{2}=0.02\right)$ and BMI groups in men $\left(F=7.27, p=.001, \omega^{2}=.02\right)$. The interaction between day of the week and age group was not significant. The LSD post-hoc test suggested that men with normal BMI achieved significantly more steps on Wednesday and Thursday compared to Sunday $(p \leq .02)$. For the overweight men, Monday was the least active day $(p \leq .01)$ compared to Tuesday, Wednesday and Friday. Moreover, overweight men achieved significantly less steps on Saturday compared to Tuesday and Wednesday $(p \leq .03)$ and on Sunday compared to Tuesday, Wednesday and Friday $(p \leq .008)$. Obese men achieved significantly more steps on Thursday compared to Saturday $(p \leq .03)$.

The repeated ANOVA showed statistically significant differences for day of the week $(F=6.38, p<.001$, $\left.\omega^{2}=0.06\right)$ and BMI groups in women $(F=17.05$, $\left.p<.001, \omega^{2}=0.05\right)$. The interaction between day of the week and BMI groups was not significant. According to the LSD post-hoc test, normal weight women achieved significantly more steps/day in all 6 days of

b) Women

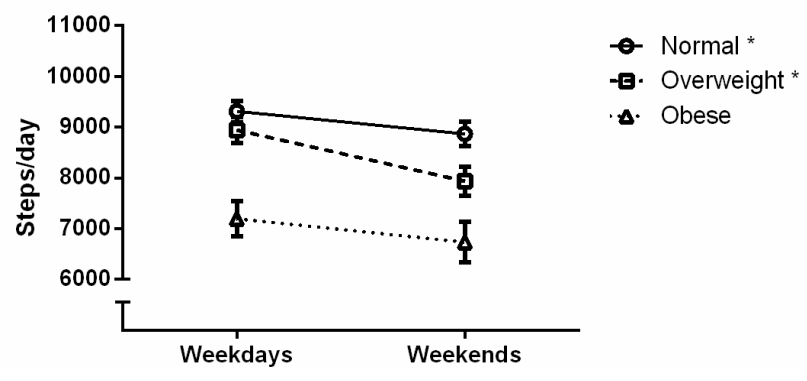

Figure 2. Differences in means and standard deviations of steps/day values on weekdays and weekend days in men (a) and women (b) of different BMI groups $(* p<.05)$.

a) Men

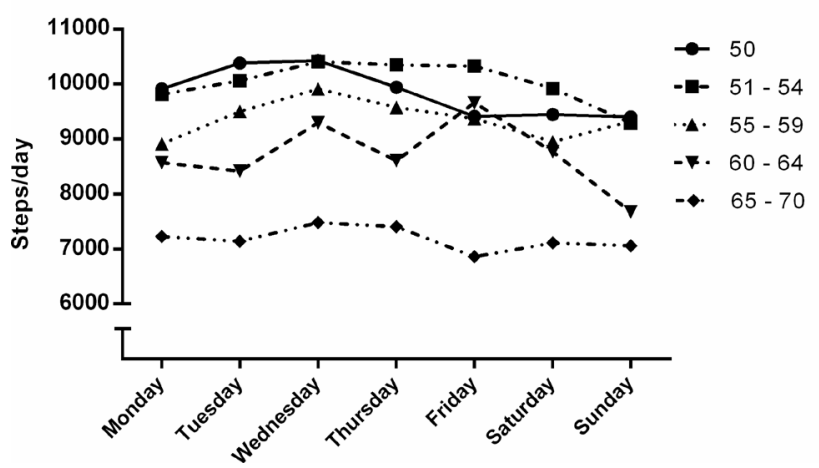

b) Women

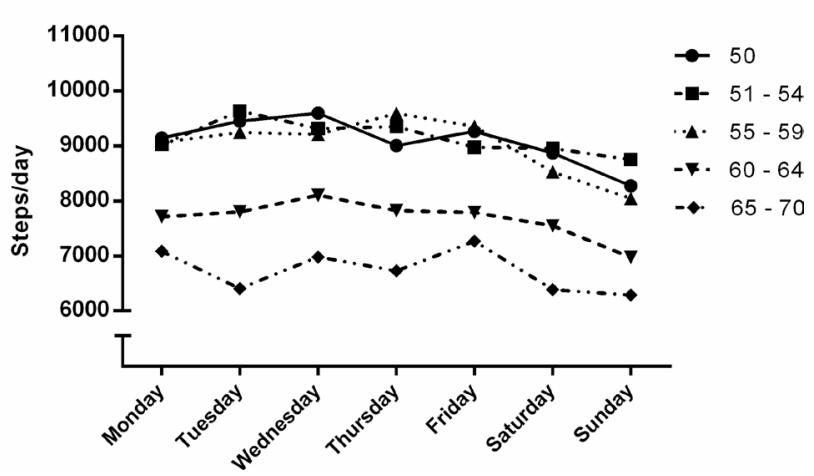

Figure 3. Variability in mean steps/day for each day of the week in five age groups in men (a) and women (b). 
a) Men

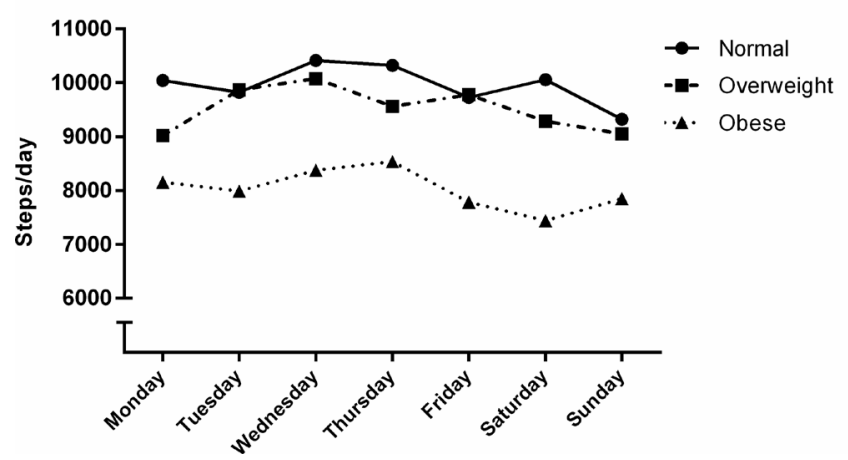

b) Women

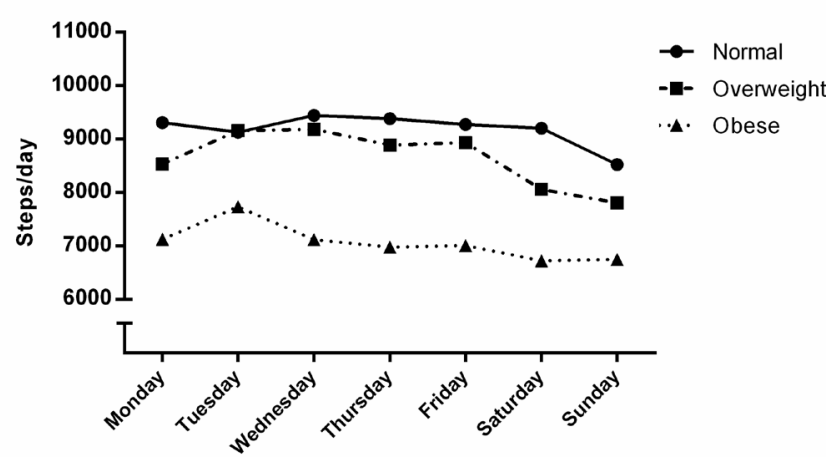

Figure 4. Variability in mean steps/day for each day of the week in three BMI groups in men (a) and women (b).

the week compared to Sunday $(p \leq .02)$. For overweight women, Sunday was the least active day compared to all five weekdays $(p \leq 0.02)$. These women achieved significantly more steps/day on Tuesday, Wednesday, Thursday and Friday compared to Saturday ( $p \leq .006)$ and on Tuesday and Wednesday compared to Monday $(p \leq .04)$. Obese women achieved significantly more steps on Tuesday $(p \leq .02)$ compared to Saturday and Sunday.

\section{Discussion}

In this cross-sectional, descriptive study, the weekdaysweekends patterns and the day-of-the-week variability in pedometer-determined physical activity in Czech inhabitants aged 50-70 years old was identified. This study confirmed the previous findings that physical activity decreases with increasing age (Craig, Russell, Cameron, \& Bauman, 2004; Sun, Norman, \& While, 2013) and that this trend is also apparent in the number of steps accumulated during a single day (TudorLocke \& Bassett, 2004; Tudor-Locke, Johnson, \& Katzmarzyk, 2009). Furthermore, results of this study were in consistency with other studies documented inverse association between BMI and number of steps achieved (Gába et al., 2009; Kroemeke et al., 2014; Swartz, Strath, Parker, Miller, \& Cieslik, 2007; TudorLocke, Burton, \& Brown, 2009).

Similar to other countries (Strycker, Duncan, Chaumeton, Duncan, \& Toobert, 2007; Tudor-Locke et al., 2004) and previous finding from the Czech Republic (Sigmundová et al., 2011) overall findings of this study in population aged 50-70 years confirmed that women and men accumulated significantly more steps on weekdays than on weekend days. However, the age group based results show that this might be true only in some groups, namely in 50-year-old men and women, in men aged 51-54 years and women aged
55-59 years. The weekdays-weekends patterns could be further explored through an analysis of the day-of-theweek variability. In this study, steps/day varied across the day of the week in both men and women in younger age groups $(\leq 64$ years $)$, whereas in the older age group (65-70 years), no significant systematic variability by day of the week was found. Less variability in physical activity in an older adult population was confirmed in several studies (Nicolai et al., 2010; Rowe et al., 2007; Togo et al., 2008). These findings are possibly related to retirement status with gender-related boundary between fulltime employment and retirement in the Czech Republic. Similar suggestions of little systematic variability in pedometer and accelerometer-determined physical activity due to day of the week in older adults in a mostly retired sample were described by Rowe et al. (2007).

In this study, the weekdays-weekends patterns and the day of the variability were examined also in individuals with different BMI. We have found differences between steps/day achieved on weekdays and weekend in both overweight men and women and in women with normal BMI. However, in obese men and women the significant weekdays-weekends difference was not identified. On the other hand, the significant variability was found in both men and women and in all groups with various BMI while examining the day-of-the-week variability. On the contrary, in a study of 122 normal weight and overweight adults from Great Britain the variability on various days of the week was observed only in overweight adults, while in adults with normal BMI the values of steps/day did not significantly differ except Sunday (Clemes et al., 2007). Similarly in this study, Sunday was the day with the lowest number of steps in all groups of women with various BMI and men with normal BMI and overweight. Only in obese men the day with the lowest step count/day was Saturday. Similarly, in a study of an adult population from Great Britain by Clemes et al. (2008) Sunday was 
the day with the lowest step count in all groups with various BMI, while the decrease in the number of steps between the other days of the week and Sunday was as many as 2,000 steps in obese individuals. Although the step-counts differences between Sunday and other days of the week were not so big, the results from the both studies point to a necessity to increase the level of physical activity on weekend days (especially on Sunday), particularly in overweight and obese individuals. The significance of this conclusion is also underpinned by dietetic studies, which document a significant increase in energy intake on weekend days (Haines, Hama, Guilkey, \& Popkin, 2003; O’Dwyer, McCarthy, Burke, \& Gibney, 2005). This simple message for risk groups in the area of public health could be one of the ways of fighting obesity.

This study brings some unique findings in the Czech Republic, however, it has some limitations. Age groups were not of the same size with the high number of fiftyyear-old participants in a separate group. Moreover, the knowledge about retirement status might confirm the suggestion about employment - retirement boundary related to the day-of-the-week variability. Our study employed only 50-70 year old participants. For the confirmation of the age related day-to-day variability, future studies should also focus on seniors older than 70 years. Moreover, the day-to-day variability can be related to season as indicated in a UK study of the adult population (Clemes et al., 2011). Hence, further study in the Czech Republic might also focus on patterns of physical activity within the four seasons of the year.

\section{Conclusion}

In conclusion, this study contributes to the evidence with the findings about the existing the day-of-the-week variability of steps counts per day in the population aged 50 to 64 years and about the absence of significant variability in seniors ( $\geq 65$ years). In this study, Sunday was the least active day in different age and BMI groups aged 50 to 70 years in a Czech population similarly as in studies of adult populations in the USA (Tudor-Locke et al., 2005) and Great Britain (Clemes et al., 2008). Hence, researchers should take the results of this study into consideration when preparing for data collection of habitual physical activity in senior populations. Moreover, the findings of the analysis should be taken into account by practitioners in the development of walking interventions and weight reduction programmes designed for this age group.

\section{Acknowledgments}

This paper was supported by the research grant of Palacký University Olomouc, Internal university grant (No. IGA_FTK_2015_003) "New technologies and approaches to physical activity monitoring: Utilization in kinanthropology research".

\section{Conflict of interest}

There were no conflicts of interest.

\section{References}

Belza, B., Walwick, J., Schwartz, S., LoGerfo, J., Shiu-Thornton, S., \& Taylor, M. (2004). Older adult perspectives on physical activity and exercise: Voices from multiple cultures. Preventing Chronic Disease, 1(4), A09.

Clemes, S. A., Griffiths, P. L., \& Hamilton, S. L. (2007). Four-week pedometer-determined activity patterns in normal weight and overweight UK adults. International Journal of Obesity, 31, 261-266.

Clemes, S. A., Hamilton, S. L., \& Griffiths, P. L. (2011). Summer to winter variability in the step counts of normal weight and overweight adults living in the UK. Journal of Physical Activity and Health, 8, 36-44.

Clemes, S. A., Hamilton, S. L., \& Lindley, M. R. (2008). Four-week pedometer-determined activity patterns in normal-weight, overweight and obese adults. Preventive Medicine, 46, 325-330.

Cohen, J. (1988). Statistical power analysis for the behavioral science (2nd ed.). Hillsdale, NJ: Erlbaum.

Craig, C. L., Russell, S. J., Cameron, C., \& Bauman, A. (2004). Twenty-year trends in physical activity among Canadian adults. Canadian Journal of Public Health, 95, 59-63.

Crouter, S. E., Schneider, P. L., Karabulut, M., \& Bassett, D. R. (2003). Validity of 10 electronic pedometers for measuring steps, distance, and energy cost. Medicine \& Science in Sports \& Exercise, 35, 1455-1460.

Cuberek, R., Gába, A., Svoboda, Z., Pelclová, J., Chmelík, F., Lehnert, M., ... Frömel, K. (2014). Walking in the lifestyle of elderly women with a sedentary occupation. Olomouc, Czech Republic: Palacký University Olomouc.

Czech Ministry of Labour and Social Affairs. (2012). Národní akční plán podporující pozitivní stárnutí pro období let 2013 až 2017 [The national action plan supporting positive aging for the period 2013-2017]. Retrieved from http://www.mpsv.cz/files/clanky/14540/NAP_20132017_070114.pdf

Czech Statistical Office. (2009). Projekce obyvatelstva České republiky do roku 2065 [Projections of population of the Czech Republic to 2065]. Retrieved from https://www. czso.cz/csu/czso/projekce-obyvatelstva-ceske-republikydo-roku-2065-n-58t98jgowg

Frömel, K., Mitáš, J., \& Kerr, J. (2009). The associations between active lifestyle, the size of a community and SES 
of the adult population in the Czech Republic. Health \& Place, 15, 447-454.

Gába, A., Pelclová, J., Přidalová, M., Riegerová, J., Dostálová, I., \& Engelová, L. (2009). The evaluation of body composition in relation to physical activity in 56-73 year old women: A pilot study. Acta Universitatis Palackianae Olomucensis. Gymnica, 39(3), 21-30.

Gába, A., \& Přidalová, M. (2015). Diagnostic performance of body mass index to identify adiposity in women. European Journal of Clinical Nutrition. Advance online publication. doi:10.1038/ejcn.2015.211

Haines, P. S., Hama, M. Y., Guilkey, D. K., \& Popkin, B. M. (2003). Weekend eating in the United States is linked with greater energy, fat, and alcohol intake. Obesity Research, 11, 945-949.

Jago, R., Anderson, C. B., Baranowski, T., \& Watson, K. (2005). Adolescent patterns of physical activity: Differences by gender, day, and time of day. American Journal of Preventive Medicine, 28, 447-452.

Kang, M., Bassett, D. R., Barreira, T. V., Tudor-Locke, C., Ainsworth, B., Reis, J. P., ... Swartz, A. (2009). How many days are enough? A study of 365 days of pedometer monitoring. Research Quarterly for Exercise and Sport, 80, 445-453.

Kroemeke, A., Zając-Gawlak, I., Pośpiech, D., Gába, A., Přidalová, M., \& Pelclová, J. (2014). Postmenopausal obesity: 12,500 steps per day as a remedy? Relationships between body composition and daily steps in postmenopausal women. Przeglad Menopauzalny (Menopause Review), 13, 227-232.

Lahti, J., Laaksonen, M., Lahelma, E., \& Rahkonen, O. (2011). Changes in leisure-time physical activity after transition to retirement: A follow-up study. International Journal of Behavioral Nutrition and Physical Activity, 8, 1-8.

Lovejoy, J., Champagne, C., De Jonge, L., Xie, H., \& Smith, S. (2008). Increased visceral fat and decreased energy expenditure during the menopausal transition. International Journal of Obesity, 32, 949-958.

Matthews, C. E., Ainsworth, B. E., Thompson, R. W., \& Bassett, D. R. Jr. (2002). Sources of variance in daily physical activity levels as measured by an accelerometer. Medicine \& Science in Sports \& Exercise, 34, 1376-1381.

Miles, L. (2007). Physical activity and health. Nutrition Bulletin, 32, 314-363.

Ng, M., Fleming, T., Robinson, M., Thomson, B., Graetz, N., Margono, C., ... \& Abraham, J. P. (2014). Global, regional, and national prevalence of overweight and obesity in children and adults during 1980-2013: A systematic analysis for the Global Burden of Disease Study 2013. Lancet, 384, 766-781.

Nicolai, S., Benzinger, P., Skelton, D. A., Aminian, K., Becker, C., \& Lindemann, U. (2010). Day-to-day variability of physical activity of older adults living in the community. Journal of Aging and Physical Activity, 18, 75-86.

O’Dwyer, N. A., McCarthy, S. N., Burke, S. J., \& Gibney, M. J. (2005). The temporal pattern of the contribution of fat to energy and of food groups to fat at various eating locations: Implications for developing food-based dietary guidelines. Public Health Nutrition, 8, 249-257.

Peiró-Velert, C., Devís-Devís, J., Beltrán-Carrillo, V. J., \& Fox, K. R. (2008). Variability of Spanish adolescents' physical activity patterns by seasonality, day of the week and demographic factors. European Journal of Sport Science, 8, 163-171.

Pelclová, J. (2015). Physical activity in the lifestyle of the adult and senior population in the Czech Republic. Olomouc, Czech Republic: Palacký University Olomouc.

Pelclová, J., El Ansari, W., \& Vašíčková, J. (2010). Study of day, month and season pedometer-determined variability of physical activity of high school pupils in the Czech Republic. Journal of Sports Science and Medicine, 9, 490-498.

Pelclová, J., Frömel, K., \& Cuberek, R. (2014). Genderspecific associations between perceived neighbourhood walkability and meeting walking recommendations when walking for transport and recreation for Czech inhabitants over 50 years of age. International Journal of Environmental Research and Public Health, 11, 527-536.

Pelclová, J., Gába, A., Tlučáková, L., \& Pośpiech, D. (2012). Association between physical activity (PA) guidelines and body composition variables in middle-aged and older women. Archives of Gerontology and Geriatrics, 55, e14-e20.

Pelclová, J., Vašičcová, J., Frömel, K., Bláha, L., Feltlová, D., Fojtík, I., ... Šebrle, Z. (2008). Vliv vybraných faktorů na pohybovou aktivitu a sezení u zaměstnaných a osob $\mathrm{v}$ důchodu ve věku 55-69 let [Influence of selected factors on physical activity and sitting in employees and retirees aged 55-69 years]. Česká kinantropologie, 12(4), 49-59.

Physical Activity Guidelines Advisory Committee. (2008). Physical activity guidelines advisory committee report. Washington, DC: U.S. Department of Health and Human Services.

Riddoch, C. J., Mattocks, C., Deere, K., Saunders, J., Kirkby, J., Tilling, K., ... Ness, A. R. (2007). Objective measurement of levels and patterns of physical activity. Archives of Disease in Childhood, 92, 963-969.

Rowe, D. A., Kemble, C. D., Robinson, T. S., \& Mahar, M. T. (2007). Daily walking in older adults: Day-to-day variability and criterion-referenced validity of total daily step counts. Journal of Physical Activity \& Health, 4, 434.

Rowlands, A. V., Pilgrim, E. L., \& Eston, R. G. (2008). Patterns of habitual activity across weekdays and weekend days in 9-11 year-old children. Preventive Medicine, 46, 317-324.

Schellenberg, G., Turcotte, M., \& Ram, B. (2005). Preparing for retirement. Canadian Social Trends, 78, 8-11.

Sheskin, D. J. (2007). Handbook of parametric and nonparametric statistical procedures (4th ed.). Boca Raton, FL: Chapman \& Hall/CRC.

Sigmundová, D., El Ansari, W., \& Sigmund, E. (2011). Neighbourhood environment correlates of physical activity: A study of eight Czech regional towns. International Journal of Environmental Research and Public Health, 8, 341-357.

Slingerland, A. S., van Lenthe, F. J., Jukema, J. W., Kamphuis, C. B., Looman, C., Giskes, K., ... Brug, J. (2007). Aging, retirement, and changes in physical activity: Prospective cohort findings from the GLOBE study. American Journal of Epidemiology, 165, 1356-1363.

Sofková, T., Přidalová, M., \& Pelclová, J. (2014). The effect of movement intervention for women attending courses in weight reduction. Acta Gymnica, 44, 47-56. 
Strycker, L. A., Duncan, S. C., Chaumeton, N. R., Duncan, T. E., \& Toobert, D. J. (2007). Reliability of pedometer data in samples of youth and older women. International Journal of Behavioral Nutrition and Physical Activity, 4, 4.

Sun, F., Norman, I. J., \& While, A. E. (2013). Physical activity in older people: A systematic review. BMC Public Health, 13, 449.

Swartz, A., Strath, S., Parker, S., Miller, N., \& Cieslik, L. (2007). Ambulatory activity and body mass index in white and non-white older adults. Journal of Physical Activity \& Health, 4, 294-304.

Togo, F., Watanabe, E., Park, H., Yasunaga, A., Park, S., Shephard, R. J., \& Aoyagi, Y. (2008). How many days of pedometer use predict the annual activity of the elderly reliably? Medicine \& Science in Sports \& Exercise, 40, 1058-1064.

Tudor-Locke, C., \& Bassett, D. R. Jr. (2004). How many steps/day are enough? Sports Medicine, 34, 1-8.

Tudor-Locke, C., Burkett, L., Reis, J. P., Ainsworth, B. E., Macera, C. A., \& Wilson, D. K. (2005). How many days of pedometer monitoring predict weekly physical activity in adults? Preventive Medicine, 40, 293-298.

Tudor-Locke, C., Burton, N. W., \& Brown, W. J. (2009). Leisure-time physical activity and occupational sitting:
Associations with steps/day and BMI in 54-59 year old Australian women. Preventive Medicine, 48, 64-68.

Tudor-Locke, C., Ham, S. A., Macera, C. A., Ainsworth, B. E., Kirtland, K. A., Reis, J. P., \& Kimsey, C. D. Jr. (2004). Descriptive epidemiology of pedometer-determined physical activity. Medicine \& Science in Sports \& Exercise, 36, 1567-1573.

Tudor-Locke, C., Johnson, W. D., \& Katzmarzyk, P. T. (2009). Accelerometer-determined steps per day in US adults. Medicine \& Science in Sports \& Exercise, 41, 1384-1391.

U.S. Department of Health and Human Services. (2000). Healthy people 2010: Understanding and improving health. Washington, DC: U.S. Government Printing Office.

Vágnerová, M. (2007). Vývojová psychologie II. [Developmental Psychology II.]. Prague, Czech Republic: Karolinum.

Van Dyck, D., Cerin, E., De Bourdeaudhuij, I., Salvo, D., Christiansen, L. B., Macfarlane, D., ... \& Davey, R. (2015). Moderating effects of age, gender and education on the associations of perceived neighborhood environment attributes with accelerometer-based physical activity: The IPEN adult study. Health \& Place, 36, 65-73.

World Health Organization. (2006). Global database on body mass index. Retrieved from http://apps.who.int/bmi/index. jsp?introPage $=$ intro.html 